Research Article

\title{
Quality Risk Propagation of Complex Product Collaborative Manufacturing Supply Chain Network Based on CN and SoV
}

\author{
Tengjiao Li (D), Hongzhuan Chen (D), Jie Yuan (D), Jingye Qian (D), and Abdul Waheed Siyal (i) \\ College of Economics and Management, Nanjing University of Aeronautics and Astronautics, Nanjing 211106, China \\ Correspondence should be addressed to Hongzhuan Chen; 13813922476@163.com
}

Received 6 August 2020; Revised 23 November 2020; Accepted 2 December 2020; Published 15 December 2020

Academic Editor: Lin-Yun He

Copyright ( $\odot 2020$ Tengjiao Li et al. This is an open access article distributed under the Creative Commons Attribution License, which permits unrestricted use, distribution, and reproduction in any medium, provided the original work is properly cited.

\begin{abstract}
The collaborative development of complex products has gradually developed into a "main manufacturer-suppliers" mode, under which the manufacturing enterprises form a complex product collaborative manufacturing supply chain network. Quality risks which bring enormous hidden danger to the product quality can be propagated and accumulate along the supply chain. It is of great significance to quantify the propagation mechanism of quality risk between supply chain network nodes and identify the key quality risk factor that causes fluctuation of product quality. This study for the first time applies the SoV into the research on quality risk propagation of complex product collaborative manufacturing supply chain network. Firstly, this paper uses the CN to construct a complex product collaborative manufacturing supply chain network according to its characteristics. Secondly, on the basis of SoV, the quality risk propagation model is established. Thirdly, we put forward a method to identify the key quality risk factors of supply chain network based on the risk propagation effect. Lastly, a numerical simulation is given to verify the effectiveness of the model and its identification method. The results reveal that the quality risk propagation includes the vertical propagation within enterprises and the horizontal propagation from the lower-level enterprises to the upper-level enterprises of the supply chain. The quality risks of an enterprise are determined by its own quality risk factors and the quality risk passed by the lower-level enterprises.
\end{abstract}

\section{Introduction}

Complex products reflect the development level of modern high-tech industries and serve as an essential symbol of a country's technological strength, including aircraft, highspeed trains, rockets, satellites, and other products and systems. The characteristics of complex products contain complex technology, strict quality requirements, high development risk, and complex project management. So, it is difficult for companies to complete the entire development process alone. In the collaborative development of complex product supply chain, the relationship between manufacturers and suppliers has changed from competition to cooperation and developed into main manufacturer-suppliers mode, forming a collaborative manufacturing supply chain network. According to the different roles and sizes of enterprises in the supply chain, the collaborative manufacturing supply chain network can be divided into four levels from low to high, which, respectively, represent parts suppliers, component suppliers, first-tier suppliers, and main manufacturers. The main manufacturer, which is in the core position of the supply chain network, leads the overall design and formulation of quality standards. And suppliers are in a subordinate position, undertaking specific development tasks.

The associated companies in the value chain form a complex product collaborative manufacturing supply chain network. The development and production of Boeing 777 and Airbus A380 is a good start for this mode. Boeing 787 and Airbus A350 are new generations of products produced under this mode. In the collaboration of main manufacturersuppliers network, the number of stakeholders is huge. For example, Boeing 787 has more than 100 suppliers from 6 countries participating in the development; Airbus A380 has more than 500 first-tier suppliers; and COMAC C919 has more than 500 domestic and foreign airliner suppliers at all 
levels. Companies gain competitive advantages through the main manufacturer-suppliers mode; however, they also face huge hidden dangers. Each supply chain node has certain quality risks due to the factors such as credit, production, supply, and demand. Quality risks propagate along the supply chain network, thus forming the "bullwhip effect" [1], namely, the phenomenon that quality risks are propagated and continuously amplified along the supply chain. This may lead to supply chain interruption or even the collapse of the entire supply chain network. Therefore, to avoid and control supply chain quality risks, it is highly significant to analyze the propagation mechanism of quality risks between nodes in a complex supply chain network in order to identify key quality risk factors that cause quality fluctuation.

Complex products require high-quality and high-reliability. Their quality risks will have a major influence on the stability and reliability of products, and lead to problems such as decline in corporate's reputation, customers' satisfaction, and sharp increases in costs. Therefore, the quality of complex products is of paramount importance. In 2013, Boeing 787 was grounded globally due to fire accidents caused by lithium battery. In 2017, China's Long March 5 Launch Vehicle failed because its hydrogen-oxygen engine did not work properly. In October 2018 and March 2019, Boeing 737MAX crashed twice due to failures in the flight control system, killing 346 people. These two air crashes not only grounded the aircraft globally but also caused huge economic losses to Boeing. In addition to the incalculable indirect losses, these crashes also created acute crisis of trust between the customers and Boeing. It can be seen from the complex product quality accidents which have occurred in recent years that the main manufacturer-suppliers mode improves the efficiency of complex product development, as well as increases the complexity of the supply chain network and the difficulty of quality risk management. Complex product development companies are supposed to meet customer needs and eliminate the quality risks at the same time. Therefore, it is particularly important to study the quality risks of complex products determined by the stakeholders of the supply chain network.

Based on the existing literature, the supply chain network quality risk of complex products presents two major characteristics as compared to the general supply chain quality risk. First, the main manufacturer and suppliers in the complex product collaborative manufacturing supply chain network are collaborative partners, and product quality depends on every supply chain network subject. Second, the number of nodes in the complex product collaborative manufacturing supply chain network is huge. The key to complex product collaborative manufacturing supply chain quality management is how to construct the network and define its quality risk factors.

How to analyze the supply chain network quality risk propagation mechanism, find out the key quality risk factors, and carry out quality risk control is also a problem that needs to be solved. Therefore, based on the characteristics of the complex product collaborative manufacturing supply chain network, this article uses the $\mathrm{CN}$ theory to establish a small world network model of the complex product collaborative manufacturing supply chain. Then, we apply the SoV to analyze the quality risk propagation mechanism of the complex product collaborative manufacturing supply chain network and identify key quality risk factors. Finally, a numerical simulation is designed to provide decisionmaking basis for avoiding and controlling quality risks and improving product quality.

The rest of the paper is organized as follows: we review the related literature about supply chain quality management, supply chain risk propagation, and SoV in Section 2. In Section 3, we analyze and construct a complex product collaborative manufacturing supply chain network. In Section 4, based on SoV, we construct the network quality risk propagation model of the complex product collaborative manufacturing supply chain to study the supply chain network quality risk propagation mechanism. Section 5 introduces the identification method of key quality risks. In Section 6, the effectiveness of the model and method is verified by numerical simulation. In the last section, we summarize the paper and present the future research directions.

\section{Literature Review}

Supply chain management is a mature research topic. With the emergence of complex products and the introduction of quality competitiveness, supply chain quality management has become a key research focus and a realistic problem that needs to be solved urgently. Carol and Manoj believed that supply chain quality management referred to the measurement, analysis and continuous improvement of product quality, processes, and services through close collaboration and integration of business processes in various links in the supply chain [2]. Hwang et al. studied a more complex supply chain quality structure; that is, suppliers implement factory inspection before products are provided to buyers. This type of supply chain quality structure is the result of further refinement of the quality in the supply chain operation [3]. Kuei et al. proposed a global supply chain quality management framework, which was an extension of traditional supplier management quality management [4]. Mahour developed a theoretical basis for supplier quality from the perspective of learning [5]. Beason proposed that the supply chain management integrated with Lean Thinking provided the source power for the sustainable development of the enterprise [6]. Hu et al. constructed a four-level agrifood supply chain, analyzed the quality decision of each participant based on Stackelberg game theory, and proposed a combination of multiple strategies to $\mathrm{co}-$ ordinate quality control in the agricultural product supply chain [7]. Wang et al. proposed a novel collaborative quality design framework for large complex product supply chain by integrating the fuzzy QFD and the grey decision-making approach [8].

The scholars used a variety of analytical frameworks to study quality management issues at different levels from the enterprises to the macro supply chain and have achieved fruitful results. However, the existing literature is mostly qualitative research, and there are few research studies on 
the quality management of complex product collaborative manufacturing supply chain.

In terms of supply chain risk propagation, Mehra studied the risk factors and propagation mechanism of supply chain quality and considered that the incentive mechanism is an important measure to solve the quality risk [9]. Helbing et al. analyzed the bullwhip effect of the supply chain network by applying the $\mathrm{CN}$ and proved that optimizing the supply chain structure can improve the stability of the network [10]. Using the conceptual model of agency theory, Cheng and Kam qualitatively analyzed the complexity of supply chain network risks [11]. Based on the financial market theory, Aliza and Alan analyzed the framework of quality risk propagation and improved the quality of the supply chain [12]. Wang et al. studied the fuzzy or accurate quality specifications of suppliers under production incentives and constructed a quality risk propagation model [13]. Li and $\mathrm{Xu}$ established an analysis model of supply chain risk propagation and conducted a quantitative study on the risk propagation process of the equipment supply chain. They revealed the change process and impact of the risk transmission process [14]. Wang studied the supplier's production incentive measures under fuzzy or exact quality specifications and constructed a quality risk propagation model [15]. From the manufacturer's perspective, Liu and Xiong proposed a method for predicting quality risks in the supply chain. They deployed quality houses through quality functions to realize quality risk factors by using support vector machines to predict [16]. Ouyang studied the diffusion and identification of quality risk in the supply chain of dairy products based on CN [17]. Based on the characteristics of quality risk propagation, Zsidisin et al. provided a framework for identifying and managing supply quality risk [18]. Based on the investigation of 31 Chinese automobile companies, Zhang et al. studied the quality risk transmission law caused by the interruption of the supply chain of the automobile industry [19]. Deng et al. explored the risk propagation mechanisms and put forward the feasible countermeasures for perishable products supply chains to improve the sustainability, which are tested by use of the case study of the yogurt supply chain in Company L [20]. Huo et al. took into account the different attitudes to enterprises at risk and the herd mechanism between enterprises, and a new model is established, which focused on research on the risk propagation mechanism of the supply chain of riskseeking enterprises and risk-averse enterprises [21]. Ojha et al. measured the behaviour of risks following the assessment of supply chain risk propagation and provided a holistic measurement approach for predicting the complex behaviour of risk propagation for improved supply chain risk management [22]. Huo et al. proposed a new model for supply chain risk propagation considering herd mentality and risk preference under warning information on multiplex networks [23]. Guo et al. took Sichuan-Tibet region as an example for empirical analysis, and simulated and analyzed the risk propagation law of the multimodal transport network under different attack types and load preferences [24].

Some achievements have been made in the research of supply chain risk propagation. However, most of them do not involve specific industry fields. There are few studies on supply chain quality risk propagation under the "main manufacturer-supplier" model of complex product. Besides, the research on the quality risk propagation mechanism and identification method of key quality risk factors is not deep enough.

The key to studying quality risk propagation is to choose a suitable method to quantify the quality risk propagation process in the supply chain. In the process of collaborative development of complex product, quality risks are transmitted by nodes to the product. After that, as the product passes along the supply chain network to the next link, quality risks may continue to accumulate in this process. SoV is a method that starts from the causes of errors, considers the transmission and accumulation effects of errors in different processes, and uses mathematical analysis to describe this effect [25]. Ding et al. conducted a lot of research on fixture optimization and measuring point optimization in machining and assembling based on the SoV [26]. Djurdjanovic and Ni analyzed the influence of errors in fixtures, locating datum features and measurement datum features on dimensional errors in machining [27]. Kim and Seun used the simulated annealing algorithm based on the state space error flow model to robustly design the multistation fixture in the mechanical assembly process [28]. Based on graph theory, computer-aided design, and processing, Liu and Jiang constructed a network structure of error transmision, which is conducive to the rapid diagnosis of error sources. However, it required a large amount of data to deduce the weight of each side, and the multiprocess engineering network structure is complex [29]. Du et al. established a three-dimensional change transmission model of rotating work pieces, which described benchmark errors, fixture errors, etc. [30]. Wang et al. established a new variation transmission model in multistage machining processes for general shape work pieces. It visually demonstrates the variation transmission chain and expands the universality of current SoV models [31]. Tang et al. proposed a new geometric error model based on the SoV theory to understand the transmission of geometric errors and the accumulation of deviations in a six-axis motion platform [32].

It can be seen from the current research that quality control and optimization based on the SoV are mainly used in machining and assembly processes. The process of collaborative development of complex product is actually a process in which the propagation and accumulation of quality risks lead to deviations in the final product. Therefore, the propagation of supply chain quality risks can be regarded as the process of error propagation and accumulation, and the SoV can be used for research.

\section{Analysis of Complex Product Collaborative Manufacturing Supply Chain Network Based on CN}

3.1. Analysis of Supply Chain Network Structure. Supply chain network refers to a network structure formed by some autonomous or semiautonomous business entities to 
produce a certain product or serve consumers through relevant upstream and downstream business relationships. Under the main manufacturer-suppliers collaborative development model, the supplier and the main manufacturer sign a contract to bear development risks together, share product profits, and form a strategic partnership with products as the link. By giving up part of noncore business and profit, the main manufacturer attracts suppliers who can share risks, so as to focus on responding to changes in market and customer needs, further improving the overall resilience of the supply chain. By integrating geographically dispersed suppliers and jointly developing products with them, a highly complex supply chain network is formed.

According to the different roles and sizes of enterprises in the supply chain, the complex product collaborative manufacturing supply chain network can be divided into four levels from low to high, which, respectively, represent parts suppliers, component suppliers, first-tier suppliers, and main manufacturers. Parts suppliers and component suppliers are at the bottom of the supply chain network. They are mainly small- and medium-sized enterprises, responsible for processing raw material and providing components for first-tier suppliers. Early first-tier suppliers were mainly responsible for the assembly and production of product subsystem components without development tasks of new products. As the increasing complexity of complex products, first-tier suppliers gradually begin to participate in development tasks, project management, product life cycle maintenance, financial management, and other businesses. The main manufacturer is at the core of the supply chain network, due to its responsibility for product design, supply chain management, enterprise coordination, and product assembly. The complex product collaborative manufacturing supply chain network structure is shown in Figure 1.

\subsection{Analysis of Complex Network Characteristics of Supply} Chain Network. Network with self-organization, self-similarity, attractors, small worlds, and some or all of the properties of scale-free networks is called complex network. With the maturity of the main manufacturer-suppliers collaborative development mode, the complex product collaborative manufacturing supply chain network gradually shows the characteristics of a complex network, mainly as follows:

(1) The complexity of the network structure: the number of nodes in the complex product collaborative manufacturing supply chain network is large. Meanwhile, the business volume and process between nodes are complex. A node at a certain level is not only the manufacturer of the lower-level nodes, but also the supplier of the upper-level nodes. And there are different purchasing, manufacturing, and sales departments within the nodes. The interaction between the internal and external structures of the system leads to the complexity of the supply chain network structure.

(2) The dynamics of the node network: nodes are connected through logistics, information flow, and contracts, and their business relationships are also undergoing dynamic changes. On the one hand, changes in the quality status of a node will affect the development status of its associated nodes. If it influences the core node, all nodes in the supply chain network may be affected, causing the supply chain to be interrupted or even the entire network to collapse. On the other hand, because of the selection mechanism of the survival of the fittest in the market, existing nodes withdrawing from the network and new ones joining the network will break the business connection between nodes or create new connections.

(3) The cross-regional nature of network nodes: with the rapid development of information technology and the improvement of logistics levels, companies in the complex product collaborative manufacturing supply chain network have broken through geographic constraints. Taking the development of large aircraft as an example, the supply chain network includes thousands of companies in more than a dozen countries. The main manufacturer conducts business cooperation with suppliers distributed in various regions of the world to form a global supply chain network. This geographical dispersion increases the difficulty of supply chain network risk management and makes the network more susceptible to interference from external uncertainties.

3.3. Construction of Supply Chain Network Based on CN. When studying a complex system containing a large number of constituent units, the units can be abstracted as nodes, and the interaction between units can be abstracted as edges. Then, the topological structure or performance of the system can be analyzed through the statistical parameters of the $\mathrm{CN}$. Based on the analysis in Sections 3.1 and 3.2, the enterprises in the supply chain network are abstracted as nodes in the $\mathrm{CN}$, the collaborative relations between enterprises are abstracted as edges, and the degree of the closeness of collaborative relations between enterprises is reflected in the weight of the edges. On this basis, the hierarchical supply chain network of main manufacturers and suppliers is constructed.

\subsubsection{Assumptions}

Assumption 1. Node's Preference Selection Mechanism. The preference selection mechanism is the basis for new nodes joining the network when they choose to cooperate with existing nodes. This paper mainly considers the factor of node strength; that is, nodes tend to choose nodes with higher node strength when connecting.

Assumption 2. Local Connection Mechanism. A node in the complex product collaborative manufacturing supply chain network may be related to the nodes of the upper or lower level, and there is no cross-level cooperation relationship between nodes of nonadjacent levels. Therefore, when 


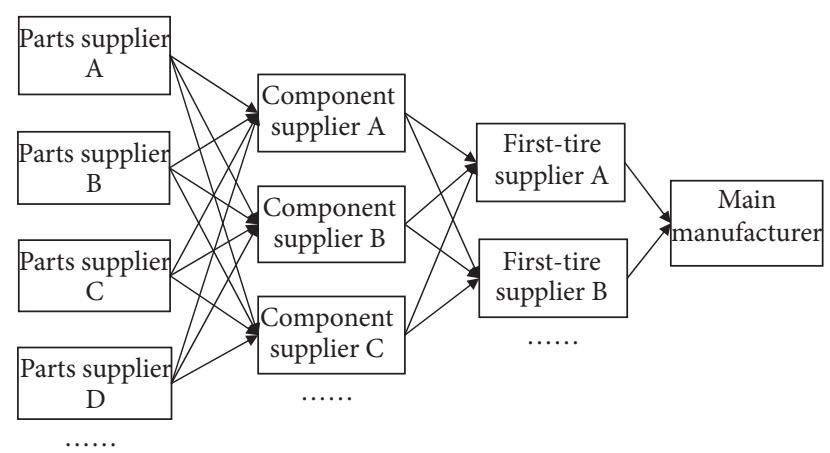

FIGURE 1: Complex product collaborative manufacturing supply chain network structure.

generating a new node, we need to determine the node type before connecting. For example, the newly joined parts manufacturer will cooperate with the component suppliers to carry out business activities, but not directly with the main manufacturer.

Assumption 3. Network Growth Mechanism. At the beginning, an initial supply chain network is often generated through a few nodes, and then new nodes are gradually added until it reaches the expected scale. During this process, some nodes withdraw from the network because of the breakdown of their partnerships or their own business problems. Therefore, not only the increase of nodes should be considered when constructing the network, but also the reduction and withdrawal of nodes. This article assumes that the supply chain network constructed is a growing network with connection preferences.

Based on the above assumptions, $G(V, R, W)$ represents the whole network, where $V, R, W$ refer to the set of nodes in the supply chain network, relationships between nodes, and the close degree of cooperation. After that, the adjacency matrix of the node relationship is established. If there is a collaborative relationship between the node $v_{i}$ and $v_{j}$, the weight of the edge is $w_{i j} \in(0,+\infty)$, and if there is no collaborative relationship, then $w_{i j}=0$. According to the structure and characteristics of the complex product collaborative manufacturing supply chain network, the network is divided into four levels. There is a collaborative relationship between nodes of two adjacent levels and no cross-level collaborative relationship between nodes of nonadjacent levels.

\subsubsection{Supply Chain Network Performance Indicators}

(1) Supply Chain Network Node Strength. The strength $S_{i}$ of node $v_{i}$ is the sum of the weights of the neighboring edges of the node, which reflects the business capabilities of the complex product collaborative manufacturing supply chain network node to a certain extent. This can be expressed as follows:

$$
S_{i}=\sum_{j=1}^{n} w_{i j},
$$

where $n$ is the number of nodes in the network and $w_{i j}$ represents the weight of the edge connecting node $v_{i}$ and $v_{j}$.

(2) Supply Chain Network Node Degree. The degree $K_{i}$ of node $v_{i}$ is the number of its adjacent edges, which represents the impact area of the supply chain node, as follows:

$$
K_{i}=\sum_{j=1}^{n} a_{i j}
$$

where $n$ is the number of nodes in the network and $a_{i j}$ is an element of the adjacency matrix. If the nodes $v_{i}$ and $v_{j}$ are connected, then $a_{i j}=1$, otherwise $a_{i j}=0$.

(3) Supply Chain Network Clustering Coefficient. The clustering coefficient of node $v_{i}$ is the ratio of the number of edges actually connected to the node and adjacent nodes to the total number of all possible edges. It reflects the degree of cooperation between the node and its associated nodes in the supply chain. Assuming that the node $v_{i}$ is directly connected to $k_{i}$ nodes, the number of edges that may exist between these nodes is $C_{k_{i}}^{2}$. The actual number of edges is represented by $E_{i}$ and the clustering coefficient is expressed as follows:

$$
C_{i}=\frac{E_{i}}{C_{k_{i}}^{2}} .
$$

\subsubsection{Supply Chain Network Construction Steps}

Step 1: set up $n$ initial nodes and divide them into four levels. The number of nodes in level $(i)$ is represented by $n_{i}$, that is $n=\sum_{i=1}^{4} n_{i}$. For example, $n_{4}=1$ means that the number of the main manufacturer node is 1 . The initial weight of the adjacent edges of the node is set to $W_{0}$. After that, a new node is added in each cycle, and it is connected to different supply chain network levels by judging the type of the node. Three constants $P_{a}, P_{b}, P_{c} \in[0,1)$ are set for this and $0 \leq P_{a}<P_{b}<P_{c}<1$.

Step 2: generate a random number $\left(r_{1}\right)$. When $r_{1}<P_{a}$, add a supply chain node to the network, and the node type is related to the number of nodes in each level of the initial supply chain, namely, the probability that the node belongs to the level $(i)$ is $p=\left(n_{i} / n\right)$. When a new node joins the supply chain network, it will bring an increment of $\delta$ to the node strength and $\delta$ is allocated according to the weight of adjacent edges. Assuming that the newly added node $v_{i}$ is connected to the node $v_{j}$, the related index changes of the node $v_{j}$ and the connected node $v_{k}$ are expressed as follows and shown in Figure 2:

$$
\begin{gathered}
w_{k j}=w_{k j}+\Delta w_{k j}, \\
S_{i j}=S_{i j}+w_{k j}+\delta,
\end{gathered}
$$




$$
\Delta w_{k j}=\delta^{*} \frac{w_{k j}}{S_{i j}} .
$$

Step 3: if $P_{a} \leq r_{1}<P_{b}$, randomly add $m$ edges to the supply chain network to simulate the establishment of a collaborative relationship with existing nodes. Since there is no cross-level collaborative relationship between nodes of nonadjacent levels, randomly added edges can only connect two nodes of adjacent levels. If the edge already exists, then increase its weight to indicate the deepening of the existing collaborative relationship. At this time, the edge strength of the connected nodes $v_{k}$ and $v_{j}$ changes as equation (4). The evolution process is shown in Figure 3. If $P_{b} \leq r_{1}<P_{c}$, the edge is deleted to simulate the situation where supply chain nodes reduce cooperation with other nodes. If $P_{c} \leq r_{1}<1$, remove supply chain node operations, in order to simulate nodes exiting the supply chain. The evolution process is shown in Figure 4.

Step 4: once the scale of the supply chain network reaches the expected requirements, the network construction is completed.

\section{Quality Risk Propagation Mechanism of Complex Product Collaborative Manufacturing Supply Chain Based on SoV}

Based on Section 3, we firstly analyze quality risks in supply chain and quality risk factors of nodes in this part. Then, we construct a quality risk propagation network. In order to study the quality risk propagation mechanism of the complex product collaborative manufacturing supply chain network, we apply the SoV to construct the quality risk propagation model.

\subsection{The Meaning and Characteristics of Supply Chain Quality} Risk. Supply chain risk is the consequence of uncertainty in the supply chain. Uncertain demand quantity, delivery cost, delivery time, and product quality all lead to supply chain risks [33]. This paper mainly considers quality risks in supply chain. Because of the complexity of quality risks in supply chain, the definitions are diverse from the different perspective of researchers. Based on previous studies, the quality risks refer to the probability of negative events caused by the conflict of quality requirements and quality reality [16]. And the quality risks are the sum of quality risks of all aspects in a supply chain [34]. Supply chain quality risks have the following characteristics that are different from other supply chain risks.

4.1.1. Directionality of Propagation. In a complex product collaborative manufacturing supply chain network, bottomlevel suppliers can propagate quality risks to the top-level main manufacturer. The propagation can be divided into two types: vertical propagation and horizontal propagation. Vertical propagation is within each node. Specifically, quality risks are propagated between different departments and different systems of the enterprise, thereby affecting the quality of its products. Horizontal propagation is outside the nodes. The quality risks are propagated to the upper nodes along with the products produced by the current node, affecting the quality of the products of subsequent nodes.

4.1.2. Superposition. This characteristic has two manifestations. One is the superposition of quality risks within the enterprise, which means the superposition of quality risks within the nodes. The other is the superposition of quality risks in different production processes. It refers to the superposition of the quality risks propagated by the current node to the subsequent node and that is of the latter's own.

4.1.3. Time Lag. Different from other risks characterized with precursory, quality risks often have an incubation period. They will only appear when their accumulation exceeds the threshold of the node's resistance to risks and may trigger a chain reaction. The quality risks may exist at any time during the collaborative development of complex products, but the time lag makes it difficult to discover them in time.

4.1.4. Difficulty in Identifying and Quantifying. Due to the network-like distribution of supply chain companies and the superposition of quality risks, the node where quality problems occur may not be the source of quality risks. Quality risk propagation is a complex systematic process, and it is difficult to quantify quality risks as corresponding indicators and use precise means to measure them.

4.2. Analysis of Node Quality Risk Factors. In a complex product collaborative manufacturing supply chain network, the quality of the final product is closely related to quality risks of each node in the supply chain. There are various uncertain risk factors inside and outside enterprises. The risk factors that may affect product quality and cause quality accidents are quality risk factors. In order to understand the quality risks of the supply chain and its propagation mechanism, it is necessary to clarify the node quality risk factors. This paper firstly summarizes the common risk factors of supply chain and then determines the node quality risk factors according to the characteristics of supply chain quality risks.

On the basis of comparing and summarizing the previous literature, the risk factors of supply chain are classified into internal risks and external risks, as shown in Table 1. The internal risks are caused by the uncertainty of enterprises, the complexity, and fragility of the supply chain system. The external risks are those which the complex and changeable environment outside the supply chain brings to enterprises and the supply chain system. 


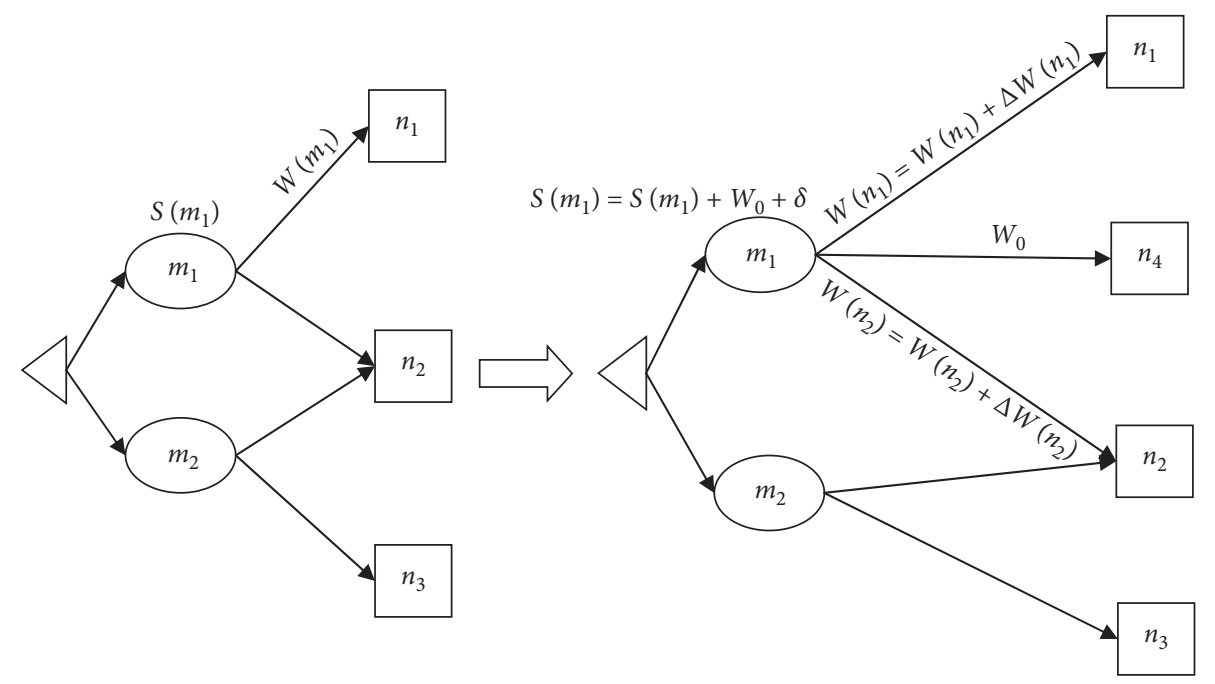

FIgURE 2: The indicator changes after new nodes are added.

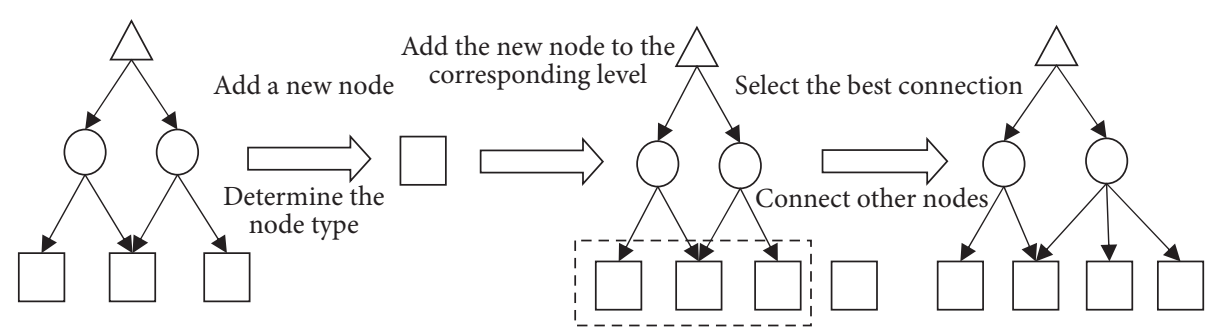

Figure 3: Add new nodes into the supply chain network.

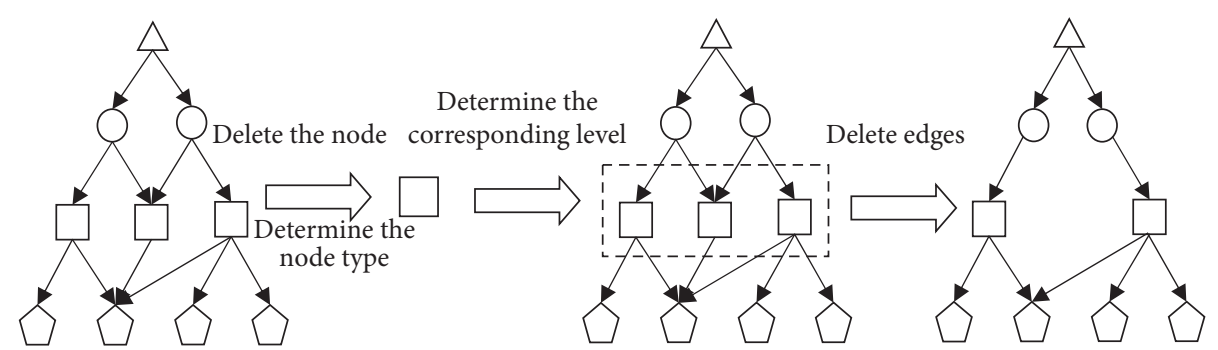

FIGURE 4: Delete supply chain network nodes.

The supply chain node quality risks are triggered by quality risk factors, which can be quantified by subrisk factors. Based on the risk factors of supply chain and characteristics of supply chain quality risks analyzed in Section 4.1, three types of node quality risk factors are summarized: credit, productive, and supply-demand quality risks. Each type contains three subrisk factors, as shown in Table 2. Credit quality risk is caused by the party who needs to carry out the contract, but according to the regulations, that party is unable to complete the quality task.

Productive quality risk exists in the production process of products. Due to strict quality standards for complex products and complex collaborative development processes, these risks are relatively difficult to avoid. Supply-demand quality risk is caused by the mismatch between the supply and demand of raw materials or products.

\subsection{Construction of Supply Chain Quality Risk Propagation Network}

4.3.1. Assumptions. In order to analyze the mechanism of quality risk propagation between supply chain nodes, we should first establish a supply chain quality risk propagation network and study the propagation method of quality risk in the supply chain. The assumptions are as follows.

Assumption 1. The cumulative effect of each node's quality risks determines the quality of the final product.

Assumption 2. Quality risks are propagated by lower-level nodes to the upper-level nodes along the supply chain.

Assumption 3. The supply chain nodes quality risk factors and subrisk factors are in a linear superposition relationship, 
TABLE 1: Risk factors of supply chain.

\begin{tabular}{lc}
\hline Classification & Risk factors \\
\hline Internal risks & $\begin{array}{c}\text { Capacity risk, reputation risk, material risk, production failure risk, production management risk, sales risk, delivery risk, } \\
\text { capital risk, logistics risk, supply risk, demand risk, organization and coordination risk, benefit distribution risk, } \\
\text { information propagation risk }\end{array}$ \\
\hline External risks & $\begin{array}{c}\text { Policy risk, legal risk, cultural conflict risk, natural environment risk, competition risk, economic environment risk, } \\
\text { information security risk }\end{array}$ \\
\hline
\end{tabular}

TABLE 2: Node quality risk factors.

\begin{tabular}{lc}
\hline Quality risk factor & Subrisk factor \\
\hline Credit quality risk & Capacity risk, reputation risk, and organization and coordination risk \\
Productive quality risk & Material risk, production failure risk, and production management risk \\
Supply-demand quality risk & Supply risk, demand risk, and information propagation risk \\
\hline
\end{tabular}

and the coupling effect between the subrisk factors is not considered.

Assumption 4. There is a collaborative relationship between nodes of two adjacent levels, and a node can be associated with multiple nodes of the upper or lower level, while there is no cross-level collaborative relationship between nodes of nonadjacent levels.

\subsubsection{Generation Rules of Supply Chain Quality Risk Propagation Network}

(1) Generation of Nodes: Consider the enterprises in the complex product collaborative manufacturing supply chain network as nodes. The network can be divided into four levels from low to high, which, respectively, represent parts suppliers, component suppliers, first-tier suppliers, and the main manufacturer. On this basis, quality risk factor and subrisk factor nodes are added. Each enterprise node is connected to three quality risk factor nodes, and each quality risk factor node is connected to three subrisk factor nodes.

(2) Generation of edges: The network edges represent the connections between supply chain nodes. The subrisk factors are connected to the quality risk factors through the edges, indicating the affiliation. The quality risk factors are connected to enterprise nodes through the edges and the enterprise nodes are connected through the edges. The directions of the edges indicate propagation directions of quality risks. The weight of each edge is represented by 0 or 1. If there is a connection between the nodes, the weight of the edge is 1 otherwise, and the weight is 0 .

According to the analysis of the characteristics of supply chain quality risk in Section 4.1, there exist both vertical and horizontal propagation of quality risks in the supply chain. The vertical propagation is carried out within the node and does not require an intermediary. Nodes are connected through collaborative elements, which are the medium for the horizontal propagation of quality risks. Quality risks are passed along with products in the supply chain. The transportation, warehousing, distribution, and other processes of the products at each node all rely on logistics. Therefore, logistics play an important role in the propagation of quality risks. Information flow is a channel for information sharing and communication between supply chain nodes. If the information is distorted, quality risks may spread from the risk source to other nodes. Supply chain nodes form a risk-sharing relationship by quality contract. Once a node has quality risks, other nodes under the quality contract framework will bear the impact of this node's quality risks. Therefore, logistics, information flow, and quality contract are all synergistic elements.

Based on the above analysis, the quality risk propagation process of the complex product collaborative manufacturing supply chain network is shown in Figure 5. $A_{k}, B_{k}, C_{k}$, respectively, represent the current node quality risk factors, that is, credit, productive, and supply-demand quality risks. $a_{k j}, b_{k j}, c_{k j}$, respectively, represent the subrisk factors of credit, productive, and supply-demand quality risks. Vertically, the subrisk factors of a node are accumulated to form quality risk factors, which act on the node's own products. Horizontally, the quality risks are propagated by lower-level nodes along the supply chain to upper-level nodes and accumulated continuously, affecting the quality of subsequent nodes' products. The quality risk of a node is composed of the quality risks propagated vertically within itself and the quality risks propagated horizontally by the lowerlevel nodes.

According to the network generation rules, the topology of the quality risk propagation network is shown in Figure 6. The blue nodes in the figure represent supply chain enterprises, the larger red nodes represent quality risk factors, and the smaller red nodes represent subrisk factors.

The network can be expressed as follows: 


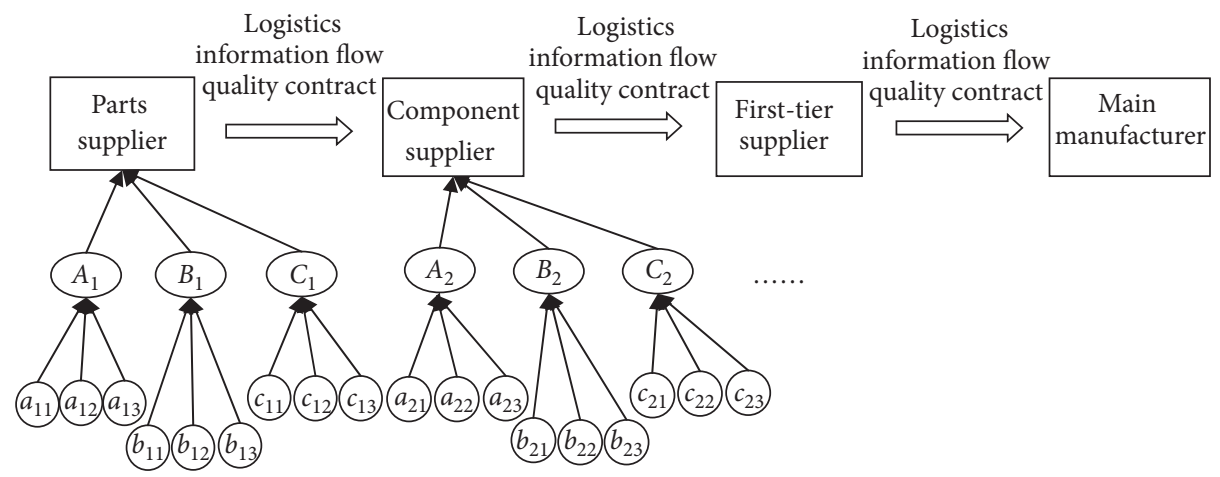

FIGURE 5: Supply chain quality risk propagation process.

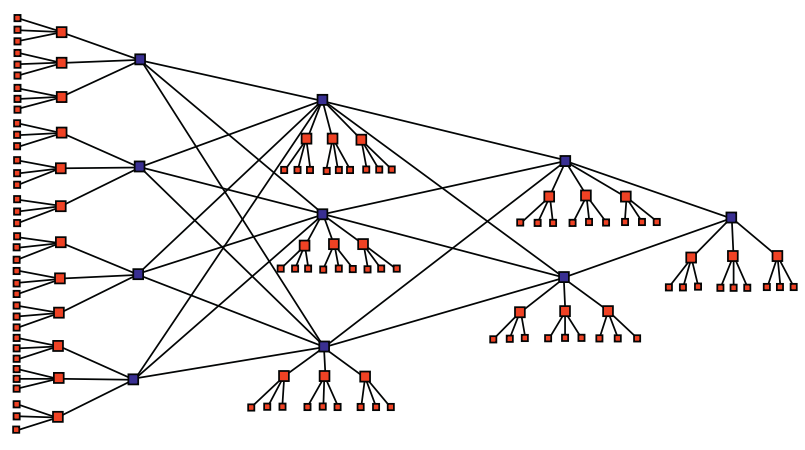

FIGURE 6: Quality risk propagation network.

$$
\begin{array}{r}
N_{0}=\langle X, Y, R, S\rangle, \\
\left\{\begin{array}{l}
X=\{P S, C S, T S, M\}, \\
Y=\{I, L, Q\}, \\
R=\left\{A_{k}, B_{k}, C_{k}\right\}, \\
S=\left\{a_{k j}, b_{k j}, c_{k j}\right\},
\end{array}\right.
\end{array}
$$

where $X=\{P S, C S, T S, M\}$ represents the set of supply chain network nodes, namely, parts suppliers, component suppliers, first-tier suppliers, and the main manufacturer. Accordingly, $Y=\{L, I, Q\}$ represent the set of collaborative elements between enterprise nodes, namely, logistics, information flow, and quality contract. Likewise, $R=\left\{A_{k}, B_{k}, C_{k}\right\}$ is the set of current node quality risk factors and $S=\left\{a_{k j}, b_{k j}, c_{k j}\right\}$ is the set of current node subrisk factors.

\subsection{Construction of Supply Chain Quality Risk Propagation} Model Based on SoV. In the supply chain network, the output quality of the current node product is the input quality of the subsequent node product, and the quality error of the current node product will affect the product quality of the subsequent nodes. The collaborative development process of complex products from raw materials to finished products is actually a process in which quality errors caused by the quality risks of each node continue to accumulate, resulting in product quality to deviate from the target. Therefore, the propagation of quality risks in the complex product collaborative manufacturing supply chain can be regarded as a process of error propagation and accumulation. This section uses the SoV to study the quality risk propagation process by quantifying the fluctuations of the node quality risks and establishes a complex product collaborative manufacturing supply chain network quality risk propagation model.

Definition 1. $Q_{k}$ represents the output quality risks of the current node, and $Q_{(k-1)}$ represents the output quality risks of the lower-level node.

Definition 2. $R_{k}$ represents the set of current node quality risk factors.

Definition 3. $R_{k}$ to $Q_{k}$ represent the vertical quality risk propagation process, and $Q_{(k-1)}$ to $Q_{k}$ represent the horizontal propagation process.

Theorem 1. In the complex product collaborative manufacturing supply chain network, the quality risk of a node is composed of the quality risks propagated vertically within itself and the quality risks propagated horizontally by the lower-level nodes. The process can be described as follows:

$$
\sigma_{Q_{k}}^{2}=\alpha_{11}^{2} \sigma_{A_{k}}^{2}+\alpha_{12}^{2} \sigma_{B_{k}}^{2}+\alpha_{13}^{2} \sigma_{C_{k}}^{2}+\sum_{r \in S_{k}} \sum_{i=1}^{m} \alpha_{2 r_{i}}^{2} \sigma_{Q_{r_{i}}}^{2} .
$$

Proof. Based on the supply chain quality risk propagation network constructed in Section 4.3, a supply chain network quality risk propagation model with $n$ nodes is constructed. For each node, consider three types of quality risk factors: credit, productive, and supply-demand factors, which are analyzed in Section 4.2. They are represented by $A_{k}, B_{k}, C_{k}$, respectively; then,

$$
\begin{aligned}
& Q_{k}=Z\left(R_{k}, Q_{(k-1)}\right), \quad k=1,2,3, \ldots, n, \\
& R_{k}=\left\{A_{k}, B_{k}, C_{k}\right\}, \quad k=1,2,3, \ldots, n .
\end{aligned}
$$

Suppose that $Z\left(R_{k}^{*}, Q_{(k-1)}^{*}\right)$ is the optimal state of node $k$ at $\left(R_{k}^{*}, Q_{(k-1)}^{*}\right)$ in the complex product collaborative manufacturing supply chain network. At this point, the second order Taylor expansion of (9) is 


$$
\begin{aligned}
Q_{k}= & Z\left(R_{k}^{*}, Q_{(k-1)}^{*}\right)+\frac{\partial Z}{\partial R_{k}} \times\left(R_{k}-R_{k}^{*}\right)+\frac{\partial Z}{\partial Q_{(k-1)}} \\
& \times\left(Q_{(k-1)}-Q_{(k-1)}^{*}\right)+\frac{\partial^{z} Z}{\partial^{2} R_{k}} \times \frac{\left(R_{k}-R_{k}^{*}\right)^{2}}{2} \\
& +\frac{\partial^{z} Z}{\partial^{2} Q_{(k-1)}} \times \frac{\left(Q_{(k-1)}-Q_{(k-1)}^{*}\right)^{2}}{2}+\frac{\partial^{z} Z}{\partial R_{k} \partial Q_{(k-1)}} \\
& \times \frac{\left(R_{k}-R_{k}^{*}\right)\left(Q_{(k-1)}-Q_{(k-1)}^{*}\right)}{2} .
\end{aligned}
$$

Make the following substitutions:

$$
\begin{aligned}
\alpha_{1} & =\frac{\partial Z}{\partial R_{k}}, \\
\alpha_{2} & =\frac{\partial Z}{\partial Q_{(k-1)}}, \\
\beta_{1} & =\frac{\partial^{z} Z}{\partial^{2} R_{k}}, \\
\beta_{2} & =\frac{\partial^{z} Z}{\partial^{2} Q_{(k-1)}}, \\
\gamma & =\frac{\partial^{z} Z}{\partial R_{k} \partial Q_{(k-1)}}, \\
\Delta R_{k} & =\left(R_{k}-R_{k}^{*}\right), \\
\Delta Q_{(k-1)} & =\left(Q_{(k-1)}-Q_{(k-1)}^{*}\right), \\
\Delta Q_{k} & =Q_{k}-Z\left(R_{k}^{*}, Q_{(k-1)}^{*}\right) .
\end{aligned}
$$

Then, there is

$$
\begin{aligned}
\Delta Q_{k}= & \alpha_{1} \Delta R_{k}+\alpha_{2} \Delta Q_{(k-1)}+\frac{\beta_{1}}{2} \Delta R_{k}^{2} \\
& +\frac{\beta_{2}}{2} \Delta Q_{(k-1)}^{2}+\frac{\gamma}{2} \Delta R_{k} \Delta Q_{(k-1)} .
\end{aligned}
$$

In the case that $R_{k}$ and $Q_{(k-1)}$ are independent of each other, the high-order part that has little effect on $\Delta Q_{k}$ can be ignored, and the result is as follows:

$$
\Delta Q_{k}=\alpha_{1} \Delta R_{k}+\alpha_{2} \Delta Q_{(k-1)} .
$$

Because of

$$
\begin{gathered}
D\left(\Delta Q_{k}\right)=\sigma_{Q_{k}}^{2}, \\
D\left(\alpha_{1} \Delta R_{k}\right)=\alpha_{1}^{2} \sigma_{R_{k}}^{2}, \\
D\left(\alpha_{2} \Delta Q_{(k-1)}\right)=\alpha_{2}^{2} \sigma_{Q_{(k-1)}}^{2}
\end{gathered}
$$

Together with (14), there is

$$
\sigma_{Q_{k}}^{2}=\alpha_{1}^{2} \sigma_{R_{k}}^{2}+\alpha_{2}^{2} \sigma_{Q_{(k-1)}}^{2} .
$$

Formula (16) illustrates the impact of the quality risk factor fluctuation of the current node and the output quality risk fluctuation of the lower-level nodes on the output quality risks of the current nodes $\alpha_{1}$ and $\alpha_{2}$ which are risk propagation coefficients. The $\sigma_{Q_{k}}^{2}$ represents the fluctuation level of the quality risk output of node $k$, that is, the variance of $Q_{k}$. The $\sigma_{R_{k}}^{2}$ represents the quality risk factors regarding fluctuation level of the node $k$, namely, the variance of $R_{k}$. And $\sigma_{Q_{(k-1)}}^{2}$ indicate the fluctuation level of the quality risk output by the lower-level nodes of node $k$, that is, the variance of $Q_{(k-1)}$.

Since $R_{k}=\left\{A_{k}, B_{k}, C_{k}\right\}$, there is

$$
\alpha_{1}^{2} \sigma_{R_{k}}^{2}=\alpha_{11}^{2} \sigma_{A_{k}}^{2}+\alpha_{12}^{2} \sigma_{B_{k}}^{2}+\alpha_{13}^{2} \sigma_{C_{k}}^{2} \text {.\#(16) }
$$

In formula (17), $\sigma_{A_{k}}^{2}, \sigma_{B_{k}}^{2}, \sigma_{C_{k}}^{2}$ represent the fluctuation levels of credit, respectively, productive, and supply-demand quality risks of node $k$. $\alpha_{11}, \alpha_{12}, \alpha_{13}$ are risk propagation coefficients of quality risk factors to node $k$. The output quality risks of $(k-1)$ nodes in the lower level are propagated to node $k$, which result in the formula

$$
\alpha_{2}^{2} \sigma_{Q_{(k-1)}}^{2}=\sum_{r \in S_{k}} \sum_{i=1}^{m} \alpha_{2 r_{i}}^{2} \sigma_{Q_{r_{i}}}^{2},
$$

where $S_{k}$ represents the set of nodes associated with node $k$, $m$ is the set of quality risk factors of node $r(r<k), \sigma_{Q_{r_{i}}}^{2}$ represents the fluctuation level of the quality risk factor $i$ of node $r$, and $\alpha_{2 r_{i}}$ is the propagation coefficient of quality risk factor $i$ of node $r$ to node $k$.

According to (17) and (18), the output quality risk fluctuation level of node $k$ is

$$
\sigma_{Q_{k}}^{2}=\alpha_{11}^{2} \sigma_{A_{k}}^{2}+\alpha_{12}^{2} \sigma_{B_{k}}^{2}+\alpha_{13}^{2} \sigma_{C_{k}}^{2}+\sum_{r \in S_{k}} \sum_{i=1}^{m} \alpha_{2 r_{i}}^{2} \sigma_{Q_{r_{i}}}^{2} .
$$

The proof is finished.

As is shown above, it can be seen that the quality risk propagation of the supply chain can be divided into the vertical propagation within nodes and the horizontal propagation from the lower-level nodes to the upper-level nodes. The quality risk will accumulate in the propagation process, and the quality risks of the current node are not only related to its own quality risk factors, but also to the quality risk passed by the lower-level nodes.

\section{Identification of Key Quality Risk Factors Based on Risk Effect}

The key quality risk factors are those which have great influence on the product quality. Identifying key quality risk factors is helpful for supply chain enterprises to avoid and control quality risks and improve product quality. Based on the quality risk propagation model constructed in Section 4, the impact of quality risk factors on final product quality risk is further quantified, and the key quality risk factors are 
determined according to the degree of influence. The following parameters are defined here:

(1) Quality risk propagation coefficient:

$$
\alpha_{i j}=\frac{K i^{\text {out }}}{K j^{\text {in }}},
$$

where $\alpha_{i j}$ is expressed by the ratio of the out degree $K i^{\text {out }}$ of node $(i)$ and the in degree $K j^{\text {in }}$ of node $j$. It represents the weight of the influence of node $(i)$ on upper-level node $j . K i^{\text {out }}$ is the number of edges from node $(i)$ to other nodes, which shows the impact of node $(i)$ on other nodes; $K j^{\text {in }}$ is the number of edges that other nodes point to node $j$, which shows the influence of other nodes on node $j$.

(2) Quality risk effect:

$$
E_{X_{i}}^{2}=\sum_{k=1}^{k \in X_{i}} r_{j n}^{2} \alpha_{i j}^{2} s_{k i}^{2} v_{k}^{2},
$$

where $E_{X_{i}}$ indicates the degree of influence of node quality risk factors on final product quality risk, and $X_{i}$ represents the set of subrisk factors of node quality risk factor $(i) . v_{k}^{2}$ is the fluctuation level of subrisk factors $k . s_{k \mathrm{i}}$ is the quality risk propagation coefficient of subrisk factor $k$ to quality risk factor $(i), \alpha_{i j}$ is the propagation coefficient of quality risk factor $i$ to node j. $r_{j n}$ is the quality risk propagation coefficient of node $j$ to the final product, which is assumed to be 1 . That being said, the quality risk of the final product is regarded as the result of the superposition of the quality risk propagated by each node to the final product. As shown in Table 3, the classification evaluation method is used to evaluate $v_{k}$.

Calculate the quality risk effect value of credit, productive, and supply-demand quality risk factors of the firstto fourth-level nodes according to (21), among which the largest one is the key quality risk factor.

\section{Numerical Simulation and Analysis}

Based on the quality risk propagation model constructed in Section 4 and the method of identifying the key quality risk factors given in Section 5, this part analyzes the quality risk propagation and the key quality risk factors of complex product collaborative manufacturing supply chain network by numerical simulation, in order to verify the effectiveness of the model and method. According to the characteristics of quality risk propagation and key quality risk factors of different level nodes, quality risk management strategies are proposed.

6.1. Numerical Simulation. Construct a supply chain network with sixteen nodes. The network consists of eight parts suppliers (first-level nodes), numbered 1 to 8 ; four component suppliers (second-level nodes), numbered 9 to 12; three first-tier suppliers (third-level nodes), numbered 13 to 15 ; and one main manufacturer (fourth-level node) numbered 16. Its topology structure is shown in Figure 7.

Select the three types of quality risk factors from Section 4.2: credit, productive, and supply-demand quality risks in $A_{k}, B_{k}$, and $C_{k}$. Each type includes three subrisk factors in $a_{k j}, b_{k j}$, and $c_{k j}$. On the basis of the supply chain network, quality risk factor and subrisk factor nodes are added. Each enterprise node is connected with three quality risk factor nodes, and each quality risk factor node is connected with three subrisk factor nodes. The structure of supply chain quality risk propagation network is the same as that in Figure 6. According to (20), the quality risk propagation coefficient matrixes of enterprise nodes are shown in Tables 4-6.

Eighteen supply chain management and quality management experts from six complex product manufacturing enterprises were investigated with the Delphi method, and the fluctuation level of risk factors at all levels was determined according to the consulting results, which are shown in Tables $7-10$.

6.2. Analysis of Quality Risk Propagation. Calculate the quality risk fluctuation level of each enterprise node according to (8). Then, add the quality risk fluctuation level of enterprise nodes at the same level from the first to the fourth, as shown in Figure 8.

Figure 8 shows the distribution of quality risk fluctuation in supply chain network. There exists quality risk fluctuation in all levels of nodes, of which the total quality risk fluctuation of the first-level node is the highest, and that of the fourth-level node is the lowest. This is consistent with the actual situation of complex product collaborative manufacturing supply chain network. In recent years, complex product quality accidents are mainly invited by the quality defects of components and parts, rather than the quality problems caused by the main manufacturer's product design and assembly. As the core node of supply chain network, the main manufacturer has strict quality management and stable quality output. The number of parts suppliers is large, and their product lines are quite different. Moreover, the technical level of parts suppliers is relatively low, so it is difficult to achieve zero defect quality control, serving as catalyst for the great fluctuation of quality output. Therefore, the quality risk of parts suppliers is the focus of quality management of complex product collaborative manufacturing supply chain.

Using (18), calculate the propagation quantity of quality risk fluctuation from lower-level enterprise nodes to upperlevel enterprise nodes, as shown in Figure 9.

As is shown in Figure 9, the propagation quantity of quality risk fluctuation between the adjacent level nodes decreases step by step, and the quantity of quality risk fluctuation propagation from the first- to second-level nodes is the largest. This is mainly because the number of lower-level nodes connected by secondary nodes is the largest, which is greatly affected by the quality risk of horizontal propagation 
TABLe 3: Classification of fluctuation level of subrisk factors.

\begin{tabular}{lcc}
\hline Fluctuation level & Description of subrisk factor status & $v_{k}$ \\
\hline Extremely low & Little fluctuation & $1 \sim 2$ \\
Low & No significant fluctuation & $3 \sim 4$ \\
Medium & Significant fluctuation & $5 \sim 6$ \\
High & Large fluctuation & $7 \sim 8$ \\
Extremely high & Extremely large fluctuation & $9 \sim 10$ \\
\hline
\end{tabular}

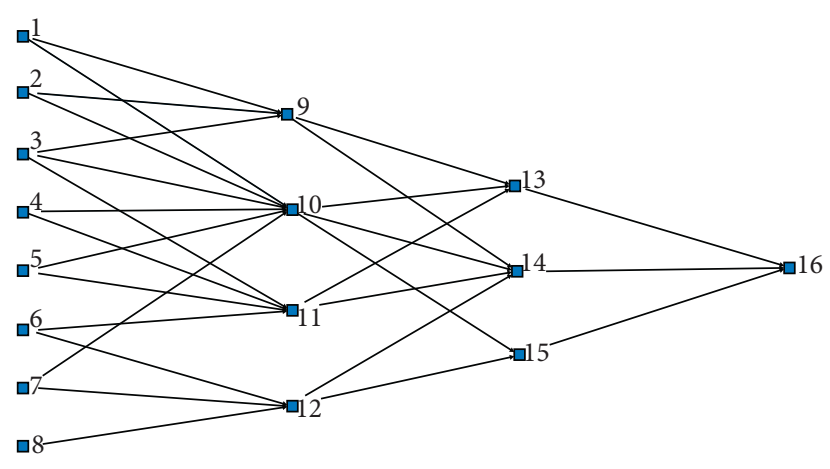

FIGURE 7: Supply chain network.

TABLE 4: Quality risk propagation coefficient matrix of the firstlevel to second-level nodes.

\begin{tabular}{lcccc}
\hline Node & 9 & 10 & 11 & 12 \\
\hline 1 & 0.3333 & 0.2222 & 0 & 0 \\
2 & 0.3333 & 0.2222 & 0 & 0 \\
3 & 0.5000 & 0.3333 & 0.4286 & 0 \\
4 & 0 & 0.2222 & 0.2857 & 0 \\
5 & 0 & 0.2222 & 0.2857 & 0 \\
6 & 0 & 0 & 0.2857 & 0.3333 \\
7 & 0 & 0.2222 & 0 & 0.3333 \\
8 & 0 & 0 & 0 & 0.1667 \\
\hline
\end{tabular}

TABLE 5: Quality risk propagation coefficient matrix of the secondlevel to third-level nodes.

\begin{tabular}{lccc}
\hline Node & 13 & 14 & 15 \\
\hline 9 & 0.3333 & 0.2857 & 0 \\
10 & 0.5000 & 0.4286 & 0.6000 \\
11 & 0.3333 & 0.2857 & 0 \\
12 & 0 & 0.2857 & 0.4000 \\
\hline
\end{tabular}

TABLE 6: Quality risk propagation coefficient matrix of the thirdlevel to fourth-level nodes.

\begin{tabular}{lc}
\hline Node & 16 \\
\hline 13 & 0.1667 \\
14 & 0.1667 \\
15 & 0.1667 \\
\hline
\end{tabular}

of lower-level nodes. Therefore, how to reduce the impact of the first-level nodes on the product quality of subsequent nodes is also an important issue in the quality management of complex product collaborative manufacturing supply chain.
6.3. Analysis of Key Quality Risk Factors. According to (21), the risk effects of three types of quality risk factors at each level are calculated, as shown in Figure 10.

As can be seen from Figure 10, there are significant differences in the risk effect of quality risk factors for different levels of nodes. The key quality risk factor of first- and secondlevel nodes is productive quality risk, the difference of risk effect of three kinds of quality risk factors of the third-level nodes is small, and the key quality risk factor of fourth-level nodes is credit quality risk. This result is in line with the actual situation of complex product collaborative manufacturing supply chain network. Parts suppliers and component suppliers are subordinate in the supply chain network, which are responsible for completing the production tasks assigned by the upper-level nodes. The quality risk mainly comes from the production process. Therefore, the impact of these enterprises on the quality risk of the final product is mainly caused by the productive quality risk. The first-tier suppliers connect with the lower-level nodes and the main manufacturer, playing a pivotal role. They not only need to complete the production and assembly tasks but also participate in the product development, project management, and other businesses. Their productive, credit, and supply-demand quality risks have a significant influence on the final products. The main manufacturer is in the core position of the supply chain network, leading the process of product design, enterprise coordination, final assembly, etc. The quality risk mainly comes from the supply chain management process, so the key quality risk of the final product is credit quality risk.

\subsection{Quality Risk Management Strategies of Complex Product Collaborative Manufacturing Supply Chain Network.} Based on the research and numerical simulation results of this paper, the quality risk control strategies are proposed from all levels of the complex product collaborative manufacturing supply chain network:

(1) Parts Supplier. The key quality risk factor of the firstlevel nodes is the productive quality risk, which should be the management focus of parts suppliers, including material risk, production failure risk, and production management risk. The specific strategies are as follows. First, strictly manage material purchasing and using process to ensure that the quality of raw materials is reliable and in line with product design standards. Second, it is of benefit for parts suppliers to regularly overhaul equipment to ensure its normal operation and timely eliminate old equipment to avoid quality accidents caused by production failure. Third, strengthening the quality training of personnel is also crucial, including the cognition of quality standard system and the improvement of skill level. Besides, consummate the quality incentive and restraint mechanism and improve the quality risk awareness of employees.

(2) Component Supplier. The key quality risk factor of the second-level nodes is productive quality risk, so the quality risk that component suppliers need to 
TABLE 7: Scoring results of subrisk factors of the first-level nodes.

\begin{tabular}{|c|c|c|c|c|c|c|c|c|c|}
\hline \multirow{2}{*}{ Node } & \multicolumn{9}{|c|}{ Subrisk factors } \\
\hline & $a_{11}$ & $a_{12}$ & $a_{13}$ & $b_{11}$ & $b_{12}$ & $b_{13}$ & $c_{11}$ & $c_{12}$ & $c_{13}$ \\
\hline 1 & 3 & 4 & 9 & 6 & 6 & 9 & 10 & 2 & 10 \\
\hline 2 & 1 & 2 & 7 & 5 & 2 & 1 & 7 & 8 & 1 \\
\hline 3 & 8 & 6 & 8 & 10 & 7 & 6 & 10 & 4 & 2 \\
\hline 4 & 1 & 2 & 7 & 7 & 10 & 7 & 1 & 9 & 1 \\
\hline 5 & 7 & 9 & 4 & 10 & 6 & 6 & 6 & 4 & 3 \\
\hline 6 & 5 & 7 & 6 & 6 & 5 & 5 & 2 & 1 & 1 \\
\hline 7 & 3 & 9 & 9 & 9 & 8 & 4 & 6 & 3 & 7 \\
\hline 8 & 7 & 8 & 1 & 5 & 1 & 7 & 7 & 1 & 6 \\
\hline
\end{tabular}

TABLE 8: Scoring results of subrisk factors of the second-level nodes.

\begin{tabular}{|c|c|c|c|c|c|c|c|c|c|}
\hline \multirow{2}{*}{ Node } & \multicolumn{9}{|c|}{ Subrisk factors } \\
\hline & $a_{21}$ & $a_{22}$ & $a_{23}$ & $b_{21}$ & $b_{22}$ & $b_{23}$ & $c_{21}$ & $c_{22}$ & $c_{23}$ \\
\hline 9 & 3 & 1 & 8 & 5 & 7 & 4 & 7 & 1 & 2 \\
\hline 10 & 2 & 7 & 9 & 4 & 2 & 3 & 1 & 10 & 5 \\
\hline 11 & 1 & 5 & 3 & 9 & 2 & 6 & 1 & 9 & 5 \\
\hline 12 & 4 & 4 & 6 & 10 & 6 & 2 & 3 & 4 & 8 \\
\hline
\end{tabular}

TABLE 9: Scoring results of subrisk factors of the third-level nodes.

\begin{tabular}{lccccccccc}
\hline Node & & \multicolumn{3}{c}{ Subrisk factors } & & & \\
& $a_{31}$ & $a_{32}$ & $a_{33}$ & $b_{31}$ & $b_{32}$ & $b_{33}$ & $c_{31}$ & 8 & $c_{33}$ \\
\hline 13 & 5 & 10 & 9 & 6 & 3 & 7 & 4 & 10 \\
14 & 10 & 4 & 3 & 10 & 1 & 4 & 7 \\
15 & 10 & 3 & 2 & 5 & 10 & 7 & 7 & 8 \\
\hline
\end{tabular}

TABLE 10: Scoring results of subrisk factors of the fourth-level nodes.

\begin{tabular}{cccccccccc}
\hline Node & \multicolumn{1}{c}{ Subrisk factors } & & & $c_{41}$ & $c_{42}$ & $c_{43}$ \\
\hline 16 & $a_{41}$ & $a_{42}$ & $a_{43}$ & $b_{41}$ & $b_{42}$ & $b_{43}$ & 5 & 4 \\
\hline
\end{tabular}

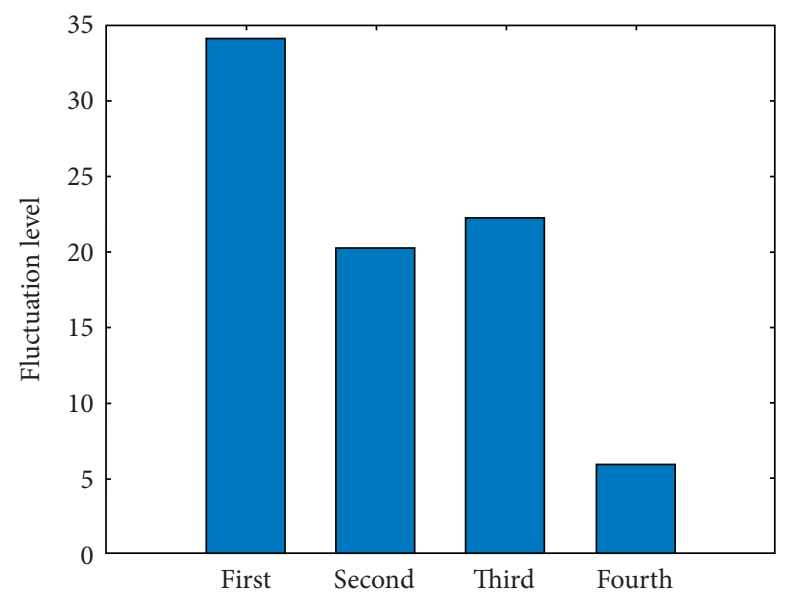

FIGURE 8: Total quality risk fluctuation of the first-level to the fourth-level nodes.

focus on management is also productive quality risk. The propagation quantity of quality risk fluctuation from the first-level nodes to the second- level nodes is the largest. Therefore, component suppliers need to be alert to the quality risk propagated by parts suppliers through collaborative 


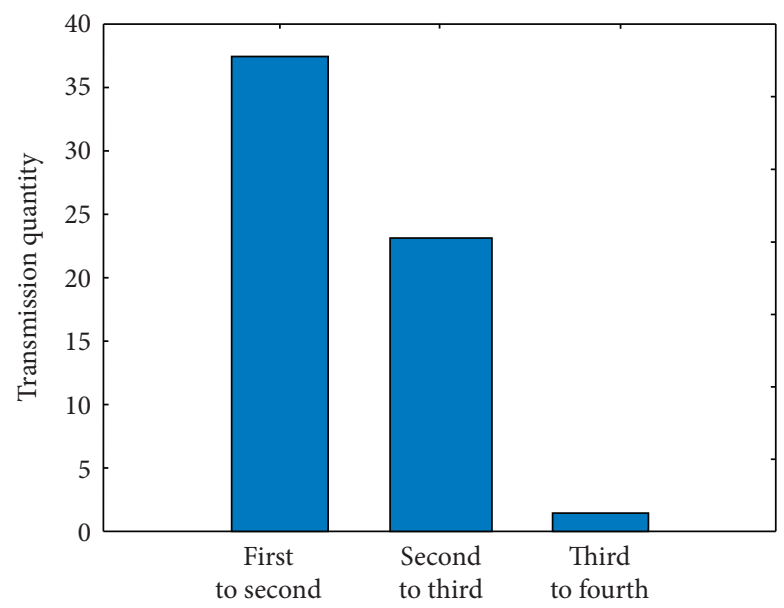

FIGURE 9: Quantity of quality risk fluctuation propagation.

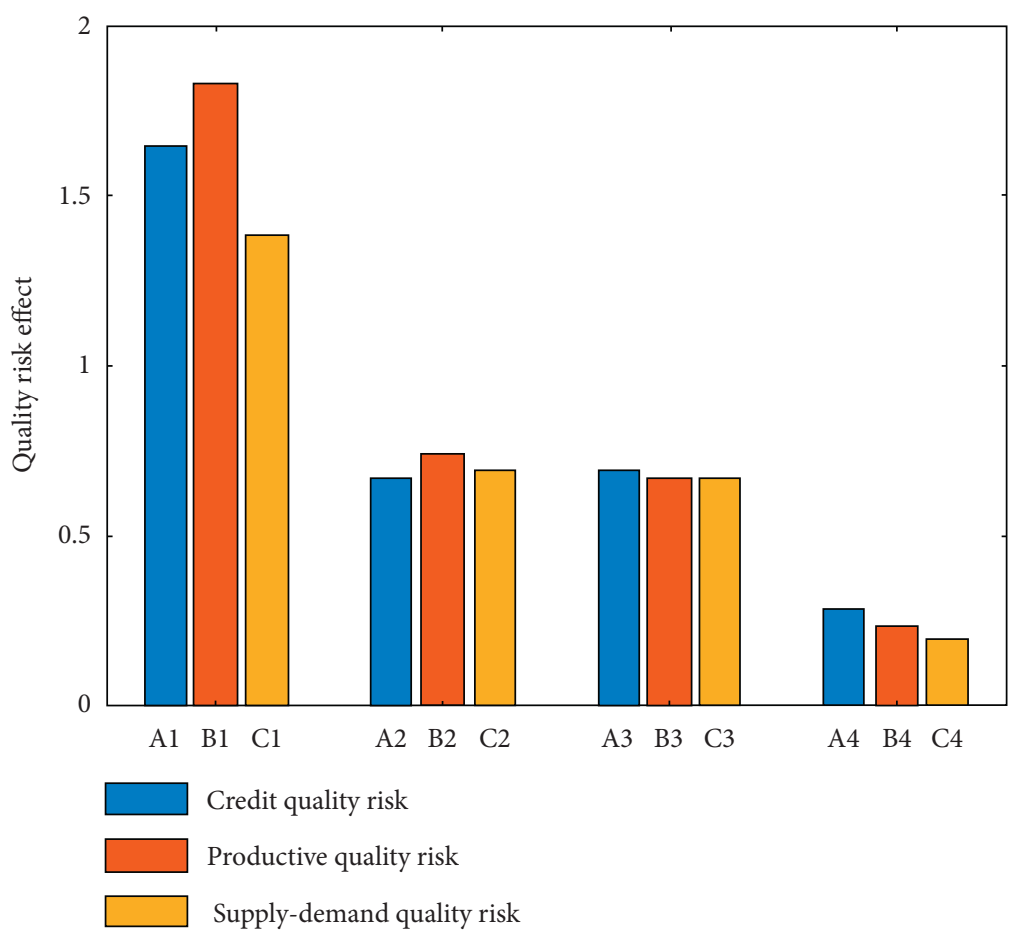

FIGURE 10: Quality risk effect.

relationship. On the basis of understanding the production technology level of parts suppliers, they should carefully establish collaboration relationship and eliminate parts suppliers with low product quality standards and large quality fluctuation, in order to improve the stability and efficiency of collaboration and reduce the propagation of quality risk along the supply chain. According to the law of quality risk propagation in the complex product collaborative manufacturing supply chain network, if the component suppliers can effectively control the horizontal quality risk propagation by parts suppliers, the risk propagation to the upper-level enterprises can be greatly reduced, which is of great significance to reduce the overall quality risk level of the network.

(3) First-Tier Supplier. The risk effect of three types of quality risk factors of the third-level nodes is very close, and the three types of quality risk factors should all be paid attention to. The first-tier supplier and the main manufacturer have direct task docking and collaborative communication. They play a pivotal role in the supply chain network. Therefore, its stable quality output is of great significance to ensure the quality of final products. First-tier suppliers can sign long-term contracts with collaborative enterprises to establish stable collaborative relations. At the same time, they should improve the information 
transparency to achieve the consistency of collaboration goals and collaboration progress.

(4) Main Manufacturer. The key quality risk factor of the fourth-level node is credit quality risk, so the main manufacturer needs to focus on managing credit quality risk, including capability risk, reputation risk, and organization coordination risk. The main manufacturer can adopt the following management strategies. First, convey the expected quality objectives of the final product to the suppliers, understand the quality objectives that the suppliers can achieve, and determine the quality contract that conforms to the capabilities of all parties. Second, the main manufacturer should clarify the rights and obligations of partners, formulate relevant flexible contracts to standardize the behaviours of all parties, improve the recognition of suppliers, and maintain a stable collaborative relationship with suppliers. Third, the strategic objectives should be coordinated with those of supply chain and suppliers as much as possible, so as to reduce the uncertainties in the implementation of the strategy and enhance the consistency of objectives with partners. Fourth, the main manufacturer can lead the construction of efficient and fast information propagation network, thus forming a stable and reliable communication mechanism with timely information feedback. On this basis, establish a quality risk early warning system of supply chain, with fluctuation threshold of quality risk set for suppliers and dynamic quality risk analysis carried out. If the analysis result exceeds the threshold value, the risk source should be found in time and measures are supposed to be taken to control the quality risk from the source.

\section{Conclusions and Future Work}

Based on the $\mathrm{CN}$ and the SoV, this paper constructs the quality risk propagation model of complex product collaborative manufacturing supply chain network and quantitatively analyzes the quality risk propagation process. We find that the quality risk propagation of complex product collaborative manufacturing supply chain network includes the vertical propagation within the enterprises and the horizontal propagation from the lower-level enterprises to the upper-level enterprises. Quality risks are accumulated in the process of propagation. The quality risks of an enterprise are determined by its own quality risk factors and the quality risk propagation from the lower-level enterprises of the supply chain. On the basis of this model, a method to identify the key quality risk factors is given, which provides decision-making basis for controlling quality risks and improving product quality level.

This study provides a new method for the quantitative study of quality risk propagation in complex product collaborative manufacturing supply chain, but there still exist some limitations. First of all, due to the limited conditions, no real quality risk data of complex product collaborative manufacturing supply chain network are used. Secondly, in the quality risk propagation model, the influence of the relationship between enterprises on the quality risk propagation is not considered. In addition, the risk resistance of supply chain network nodes can be studied in the future, so as to put forward more targeted quality risk management strategies.

\section{Data Availability}

The data used to support the findings of this study are available from the corresponding author upon request.

\section{Conflicts of Interest}

The authors declare that they have no conflicts of interest.

\section{Acknowledgments}

This work was supported by the National Social Science Foundation of China (no. 19BJY094), the National Natural Science Foundation of China (no. 71573115), the Ministry of Education General Research Project in Humanities and Social Sciences (no. 18YJA630008), the Fundamental Research Funds for the Central Universities (no. NP2019202), and the Quality Engineering Innovation Zone and the Undergraduate Innovation Training Program of Nanjing University of Aeronautics and Astronautics (no. 2020CX00919).

\section{References}

[1] H. L. Lee, V. Padmanabhan, and S. J. Whang, "Information distortion in a supply chain: the bullwhip effect," Management Science, vol. 43, no. 4, pp. 546-558, 1997.

[2] J. R. Carol and K. M. Manoj, "Defining the concept of supply chain quality management and its relevance to academic and industrial practice," International Journal of Production Economics, vol. 96, no. 3, pp. 315-337, 2005.

[3] I. Hwang, S. Radhakrishnan, and L. Su, "Vendor certification and appraisal: implications for supplier quality," Management Science, vol. 52, no. 10, pp. 1472-1482, 2006.

[4] C.-H. Kuei, C. N. Madu, and C. Lin, "Developing global supply chain quality management systems," International Journal of Production Research, vol. 49, no. 15, pp. 4457-4481, 2011.

[5] M. P. Mahour, "Supply chain quality management," The International Journal of Quality \& Reliability Management, vol. 30, no. 5, pp. 511-529, 2013.

[6] M. G. Beason, "Lean machining-integrating the supply chain," Manufacturing Engineering, vol. 151, no. 2, pp. 75-79, 2013.

[7] J.-Y. Hu, J. Zhang, M. Mei, W. M. Yang, and Q. Shen, "Quality control of a four-echelon agri-food supply chain with multiple strategies," Information Processing in Agriculture, vol. 6, no. 4, pp. 425-437, 2019.

[8] H. Wang, Z. G. Fang, D. A. Wang, and S. F. Liu, "An integrated fuzzy QFD and grey decision-making approach for supply chain collaborative quality design of large complex products," Computers \& Industrial Engineering, vol. 140, 2020.

[9] S. Mehra, "Current issues and emerging trends in supply chain management: an editorial perspective," International Journal of Production Research, vol. 43, no. 16, pp. 3299-3302, 2005. 
[10] D. Helbing, D. Armbruster, A. S. Mikhallov, and E. Lefeber, "Information and material flows in complex networks," Physica A-Statistical Mechanics and its Applications, vol. 363, no. 1, pp. 11-18, 2006.

[11] S. K. Cheng and B. H. Kam, "A conceptual framework for analysing risk in supply networks," Journal of Enterprise Information Management, vol. 21, no. 4, pp. 345-360, 2008.

[12] H. Aliza and K. Alan, "Financial uncertainty in supply chain models," Operations Research \& Management Science, vol. 151, pp. 185-203, 2011.

[13] X. Wang, D. Li, and X. Shi, "A fuzzy model for aggregative food safety risk assessment in food supply chains," Production Planning \& Control, vol. 23, no. 5, pp. 377-395, 2012.

[14] S. Li and A. Q. Xu, "Research of equipment supply chain risk transmission," Journal of Academy of Armored Force Engineering, vol. 27, no. 4, pp. 21-26, 2013.

[15] Y. Wang, "Specification vagueness and supply quality risk," Naval Research Logistics (NRL), vol. 60, no. 3, pp. 222-236, 2013.

[16] C. H. Liu and W. Xiong, "Modelling and simulation of quality risk forecasting in a supply chain," International Journal of Simulation Modelling, vol. 14, no. 2, pp. 359-370, 2015.

[17] X. J. Ouyang, Research on Diffusion Mechanism and Identification Method of Quality Risk in the Dairy Supply Chain, Beijing Jiao Tong University, Beijing. China, 2016.

[18] G. A. Zsidisin, B. Petkova, L. W. Saunders, and M. Bisseling, "Identifying and managing supply quality risk," The International Journal of Logistics Management, vol. 27, no. 3, pp. 908-930, 2016.

[19] J. Zhang, X. Chen, and C. Fang, “Transmission of a supplier's disruption risk along the supply chain: a further investigation of the Chinese automotive industry," Production Planning \& Control, vol. 29, no. 9, pp. 773-789, 2018.

[20] X. Deng, X. Yang, Y. Zhang, Y. Li, and Z. Lu, "Risk propagation mechanisms and risk management strategies for a sustainable perishable products supply chain," Computers \& Industrial Engineering, vol. 135, pp. 1175-1187, 2019.

[21] L. A. Huo, H. Y. Guo, and Y. Y. Cheng, "Supply chain risk propagation model considering the herd mentality mechanism and risk preference," Physica A: Statistical Mechanics and Its Applications, vol. 529, 2019.

[22] R. Ojha, A. Ghadge, M. K. Tiwari, and U. S. Bititci, "Bayesian network modelling for supply chain risk propagation," International Journal of Production Research, vol. 56, no. 17, pp. 5795-5819, 2018.

[23] L. A. Huo, H. Y. Guo, and Y. Y. Cheng, "A new model for supply chain risk propagation considering herd mentality and risk preference under warning information on multiplex networks," Physica A: Statistical Mechanics and Its Applications, vol. 545, 2020.

[24] J. N. Guo, J. X. Xu, Z. G. He, and W. Liao, "Research on risk propagation method of multimodel transport network under uncertainty," Physica A: Statistical Mechanics and Its Applications, vol. 563, 2020.

[25] C. H. Liu, Study on Stream of Variation Modeling and Robust Control Method for Complex Thin-Walled Parts in the Investment Casting Process, Shanghai Jiao Tong University, Shanghai, China, 2016.

[26] Y. Ding, P. Kim, and D. Ceglarek, "Optimal sensor distribution for variation diagnosis in multistation assembly processes," IEEE Transactions on Robotics and Automation, vol. 19, no. 4, pp. 543-556, 2003.

[27] D. Djurdjanovic and J. Ni, "Dimensional errors of fixtures, locating and measurement datum features in the stream of variation modeling in machining," Journal of Manufacturing Science and Engineering, vol. 125, no. 4, pp. 716-730, 2003.

[28] P. Kim and J. U. Seun, "Multi-station fixture layout design using simulated annealing," Management Science and Financial Engineering, vol. 10, no. 2, pp. 73-87, 2004.

[29] D. Liu and P. Jiang, "The complexity analysis of a machining error propagation network and its application," Proceedings of the Institution of Mechanical Engineers, Part B: Journal of Engineering Manufacture, vol. 223, no. 6, pp. 623-640, 2009.

[30] S. Du, X. Yao, D. Huang, and M. Wang, "Three-dimensional variation propagation modeling for multistage turning process of rotary workpieces," Computers \& Industrial Engineering, vol. 82, pp. 41-53, 2015.

[31] K. Wang, S. Du, and L. Xi, "Three-dimensional tolerance analysis modelling of variation propagation in multi-stage machining processes for general shape workpieces," International Journal of Precision Engineering and Manufacturing, vol. 21, no. 1, pp. 31-44, 2020.

[32] H. Tang, J.-A. Duan, and S. Lu, "Stream-of-variation (SoV) theory applied in geometric error modeling for six-axis motion platform," IEEE Transactions on Systems, Man, and Cybernetics: Systems, vol. 50, no. 3, pp. 762-770, 2020.

[33] J. Hallikas, I. Karvonen, U. Pulkkinen, V.-M. Virolainen, and M. Tuominen, "Risk management processes in supplier networks," International Journal of Production Economics, vol. 90, no. 1, pp. 47-58, 2004.

[34] L.-N. Wang and L.-L. Lu, "Research on coordination in supply chain for perishable goods based on quality risk," Advances in Intelligent and Soft Computing, vol. 161, pp. 501-509, 2012. 